\title{
Short-Term Safety and Plasma Concentrations of Edoxaban in Japanese Patients With Non-Valvular Atrial Fibrillation and Severe Renal Impairment
}

\author{
Yukihiro Koretsune, MD; Takeshi Yamashita, MD; Tetsuya Kimura; \\ Masayuki Fukuzawa; Kenji Abe; Masahiro Yasaka, MD
}

\begin{abstract}
Background: The short-term safety and plasma concentrations of edoxaban $15 \mathrm{mg}$ once daily in Japanese patients with non-valvular atrial fibrillation (NVAF) and severe renal impairment (SRI; creatinine clearance [CLCR] $\geq 15$ to $<30 \mathrm{ml} / \mathrm{min}$ ) were compared with those in NVAF patients with normal renal function or mild renal impairment (normal/ $\mathrm{MiRl}$; CLCR $\geq 50 \mathrm{ml} / \mathrm{min}$ ) treated with edoxaban 30 or $60 \mathrm{mg}$.

Methods and Results: In this Phase 3 multicenter open-label 3 parallel-group study, SRI patients received oncedaily edoxaban $15 \mathrm{mg}(\mathrm{n}=50)$, whereas normal/MiRI patients were randomized to receive either once-daily edoxaban 30 or $60 \mathrm{mg}$ ( $\mathrm{n}=22$ and 21 , respectively) for 12 weeks. Plasma edoxaban concentrations and biomarkers of blood coagulation and fibrinolysis were measured. Adverse events and thromboembolic events were recorded throughout the study. Rates of any bleeding were comparable between SRI patients receiving edoxaban $15 \mathrm{mg}(20.0 \%)$ and normal/MiRI patients receiving edoxaban 30 or $60 \mathrm{mg}(22.7 \%$ and $23.8 \%$, respectively). No major bleeding or thromboembolic events occurred in any treatment group. Similar plasma concentrations and biomarker profiles were observed in SRI patients receiving edoxaban $15 \mathrm{mg}$ and normal/MiRI patients receiving edoxaban 30 or $60 \mathrm{mg}$.
\end{abstract}

Conclusions: In this 12-week short-term study in Japanese NVAF patients with SRI, edoxaban $15 \mathrm{mg}$ once daily exhibited similar safety, plasma concentration, and biomarker profiles as did the 30-mg and 60-mg doses in patients with normal/MiRI. (Circ J 2015; 79: 1486-1495)

Key Words: Anticoagulants; Atrial fibrillation; Edoxaban; Renal impairment

$\mathbf{I}$ n Japan, atrial fibrillation (AF) occurs in $1.0 \%$ of adults aged $60-69$ years, and in $3.2 \%$ of adults $\geq 80$ years of age. ${ }^{1}$ In addition, many older individuals have renal impairment; approximately $45 \%$ of Japanese adults $\geq 80$ years of age have chronic kidney disease (CKD), defined as an estimated glomerular filtration rate $<60 \mathrm{ml} / \mathrm{min} / 1.73 \mathrm{~m}^{2} .^{2}$ Importantly, renal impairment is an independent risk factor for stroke and systemic embolic events (SEE) in patients with AF. ${ }^{3,4}$ Recently, non-vitamin $\mathrm{K}$ antagonist oral anticoagulants (NOACs; direct thrombin or direct factor Xa inhibitors) have been recommended for stroke prevention in patients with AF. ${ }^{5}$ However, data regarding the use of NOACs for stroke prevention in Japanese patients with AF and severe renal impairment (SRI; creatinine clearance $[\mathrm{CLCR}] \geq 15$ to $<30 \mathrm{ml} / \mathrm{min}$ ) are limited. ${ }^{6-8}$

\section{Editorial $p 1441$}

Edoxaban is a novel, oral, direct factor Xa inhbitor.9 Approximately $50 \%$ of the absorbed edoxaban dose is eliminated renally. ${ }^{10}$ Modeling and simulation analyses, which included data from a Phase 2 study in patients with non-valvular $\mathrm{AF}$ (NVAF), revealed that moderate renal impairment (CLCR $\geq 30$ to $<50 \mathrm{ml} / \mathrm{min}$ ) was associated with increased edoxaban plasma concentrations. ${ }^{11}$ In the global Phase 3 Effective Anticoagulation with Factor Xa Next Generation in Atrial Fibrillation (ENGAGE AF)-TIMI 48 trial, both the 30- and 60-mg once-daily dosing regimens of edoxaban were noninferior to warfarin for the prevention of stroke and SEE, and associated with significantly lower bleeding rates. ${ }^{12}$ The dose of edoxaban was reduced by $50 \%$ in patients with moderate renal impairment, while patients with SRI were excluded from the ENGAGE AF trial. Therefore, information regarding the safety and efficacy of edoxaban in NVAF patients with SRI is limited.

Received August 26, 2014; revised manuscript received March 5, 2015; accepted March 6, 2015; released online April 28, 2015 Time for primary review: 15 days

Institute for Clinical Research, National Hospital Organization, Osaka National Hospital, Osaka (Y.K.); The Cardiovascular Institute, Tokyo (T.Y.); Clinical Planning Department (T.K.), Clinical Execution Department (M.F.), Clinical Data \& Biostatistics Department (K.A.), Daiichi Sankyo Co Ltd, Tokyo; and Department of Cerebrovascular Medicine and Neurology, National Hospital Organization, Kyushu Medical Center, Fukuoka (M.Y.), Japan

Mailing address: Yukihiro Koretsune, MD, Institute for Clinical Research, National Hospital Organization, Osaka National Hospital, 2-1-14 Hoenzaka, Chuo-ku, Osaka 540-0006, Japan. E-mail: koretune@onh.go.jp

ISSN-1346-9843 doi:10.1253/circj.CJ-14-0942

All rights are reserved to the Japanese Circulation Society. For permissions, please e-mail: cj@j-circ.or.jp 


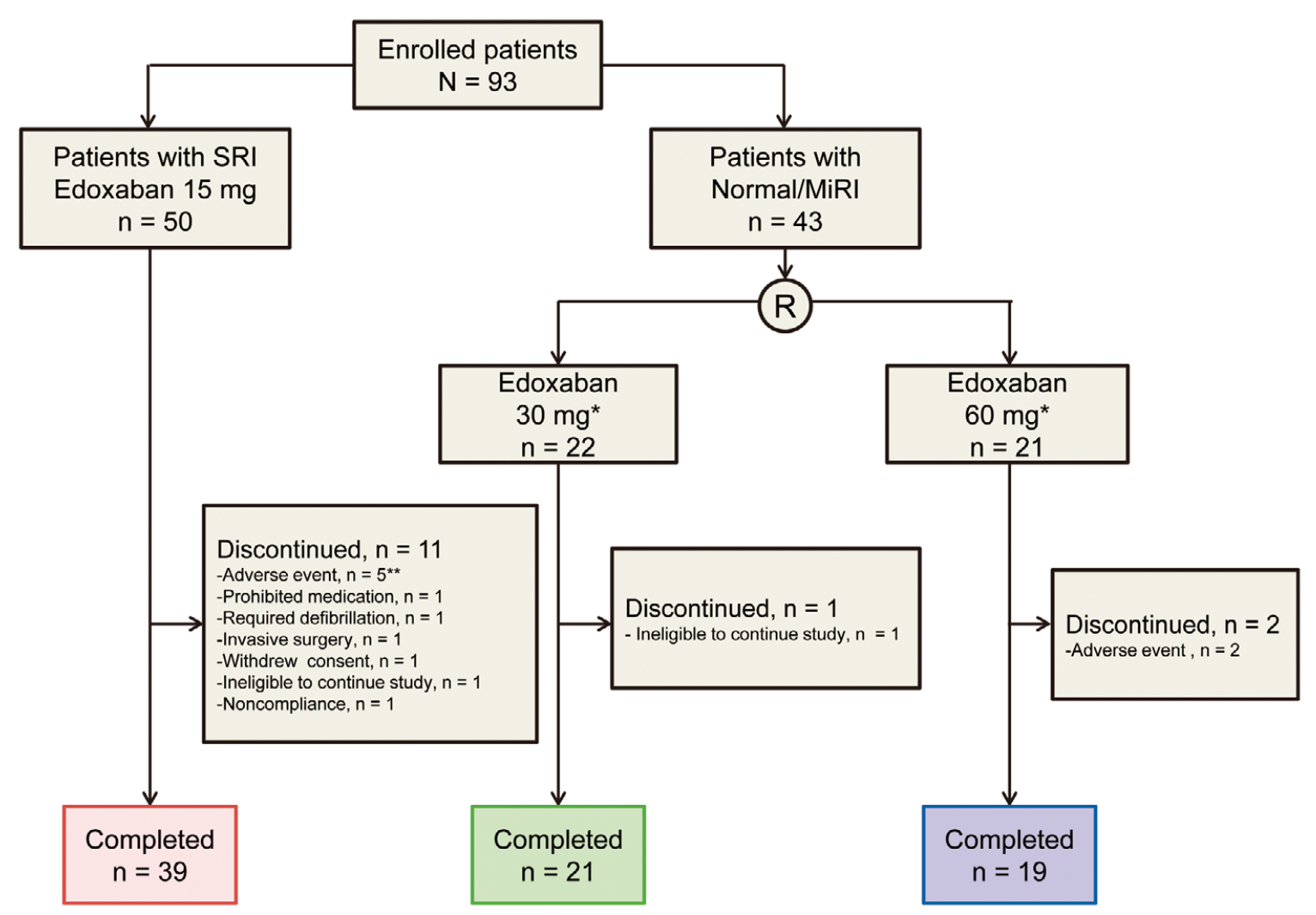

Figure 1. Patient disposition. *Eight patients each in the normal renal function or mild renal impairment (normal/MiRI) edoxaban 30-mg and 60-mg groups had a 50\% dose reduction, to 15- and 30-mg edoxaban, respectively; 7 dose-reduced patients in each group completed the study. ${ }^{*}$ Of the 5 patients in the severe renal impairment (SRI) edoxaban 15-mg group who discontinued, 2 did so because of a decrease in creatinine clearance to $<15 \mathrm{ml} / \mathrm{min}$. $\mathrm{R}$, randomized.

The objective of the present study was to evaluate the shortterm safety and plasma concentrations of edoxaban after administration of a reduced dose of $15 \mathrm{mg}$ once daily in Japanese NVAF patients with SRI in comparison with the administration of edoxaban 30 or $60 \mathrm{mg}$ once daily in NVAF patients with normal renal function or mild renal impairment (normal/MiRI; CLcR $\geq 50 \mathrm{ml} / \mathrm{min}$ ).

\section{Methods}

\section{Study Design}

The present study was a Phase 3 multicenter open-label, 3 parallel-group study (clinicaltrials.gov ID: NCT\# 01857622). Patients with SRI were administered edoxaban $15 \mathrm{mg}$ once daily (SRI 15-mg group). Patients with normal/MiRI were randomized $1: 1$ to receive either edoxaban 30 or $60 \mathrm{mg}$ once daily. In the normal/MiRI groups, a $50 \%$ dose reduction occurred at randomization in patients with body weight $\leq 60 \mathrm{~kg}$ or treated concomitantly with the P-glycoprotein (P-gp) inhibitors quinidine or verapamil (Supplementary File 1).

Treatment duration was 12 weeks, with a follow-up assessment 2 weeks after the end of treatment. Patients already receiving warfarin for thromboprophylaxis were switched to edoxaban. Dose-adjusted warfarin treatment was initiated or resumed at the end of the study (Supplementary File 1).

The study was conducted in compliance with the Declara- tion of Helsinki, Good Clinical Practice (GCP) regulations and guidelines, and all applicable local regulations. All protocols and study procedures, written patient information, and informed consent forms were approved by institutional review boards. All patients provided written informed consent prior to participation in any study evaluations.

\section{Patient Selection}

Men and women $\geq 20$ years of age with a history of NVAF (documented by electrical tracing within the past 12 months) for whom anticoagulant therapy was indicated, a $\mathrm{CHADS}_{2}$ score $\geq 1$, and CLCR of either $\geq 15$ to $<30 \mathrm{ml} / \mathrm{min}$ (SRI) or $\geq 50 \mathrm{ml} / \mathrm{min}$ (normal/MiRI) were enrolled in the study. In the present study, CLCR was calculated using the Cockcroft-Gault formula. ${ }^{13}$

Patients were excluded from the study if they were undergoing or planning to start hemodialysis, if they were at risk for bleeding, or if they were receiving other anticoagulant therapy (except warfarin, rivaroxaban, or dabigatran). Additional details of exclusion criteria are provided in the Supplementary Material. Patients were discontinued from study treatment if hemodialysis became necessary or CLCR decreased to $<15 \mathrm{ml} / \mathrm{min}$. In addition, patients already receiving warfarin who were to switch to edoxaban but did not achieve a prothrombin time (PT) expressed as an international normalized ratio (PT-INR) $<2.02$ weeks after warfarin ces- 


\begin{tabular}{|c|c|c|c|}
\hline & \multirow{2}{*}{$\begin{array}{c}\text { SRI } \\
\qquad \begin{array}{c}\text { Edoxaban } 15 \mathrm{mg} \\
(\mathrm{n}=50)\end{array}\end{array}$} & \multicolumn{2}{|c|}{ Normal/MiRI† } \\
\hline & & $\begin{array}{c}\text { Edoxaban } 30 \mathrm{mg} \\
(\mathrm{n}=22)\end{array}$ & $\begin{array}{c}\text { Edoxaban } 60 \mathrm{mg} \\
(\mathrm{n}=21)\end{array}$ \\
\hline No. males & $28(56.0)$ & $18(81.8)$ & $14(66.7)$ \\
\hline Mean $( \pm S D)$ age (years) & $80.9 \pm 6.0$ & $68.0 \pm 8.9$ & $72.2 \pm 4.6$ \\
\hline \multicolumn{4}{|l|}{ Body weight (kg) } \\
\hline$\leq 60$ & 38 (76.0) & $8(36.4)$ & $8(38.1)$ \\
\hline$>60$ & $12(24.0)$ & $14(63.6)$ & $13(61.9)$ \\
\hline Mean \pm SD & $54.4 \pm 9.5$ & $65.0 \pm 12.3$ & $67.0 \pm 11.5$ \\
\hline \multicolumn{4}{|l|}{$\mathrm{CLCR}_{\mathrm{C}}(\mathrm{ml} / \mathrm{min})$} \\
\hline$\geq 15$ to $<30$ & $50(100.0)$ & NA & NA \\
\hline$\geq 50$ to $\leq 80$ & NA & $15(68.2)$ & $15(71.4)$ \\
\hline$>80$ & NA & $7(31.8)$ & $6(28.6)$ \\
\hline Mean \pm SD & $25.5 \pm 3.6$ & $74.0 \pm 24.4$ & $68.3 \pm 12.8$ \\
\hline Median (minimum-maximum) & $26.3(17.2-29.9)$ & $64.4(50.3-141.1)$ & $62.5(52.0-92.3)$ \\
\hline Quinidine or verapamil use at baseline & $4(8.0)$ & $0(0.0)$ & $2(9.5)$ \\
\hline Warfarin use at baseline & $48(96.0)$ & $20(90.9)$ & $17(81.0)$ \\
\hline \multicolumn{4}{|l|}{ CHADS$_{2}$ score } \\
\hline$\leq 3$ & $28(56.0)$ & $22(100.0)$ & $19(90.5)$ \\
\hline$\geq 4$ & $22(44.0)$ & $0(0.0)$ & $2(9.5)$ \\
\hline Mean \pm SD & $3.5 \pm 1.2$ & $1.7 \pm 0.9$ & $2.0 \pm 1.1$ \\
\hline \multicolumn{4}{|l|}{ Concomitant use of: } \\
\hline Amiodarone & $5(10.0)$ & $1(4.5)$ & $1(4.8)$ \\
\hline Aspirin & $15(30.0)$ & $2(9.1)$ & $2(9.5)$ \\
\hline NSAIDs & $4(8.0)$ & $2(9.1)$ & $2(9.5)$ \\
\hline
\end{tabular}

Unless indicated otherwise, data are presented as $\mathrm{n}(\%)$. tEight patients each in the normal renal function or mild renal impairment (normal/MiRl) edoxaban $30-\mathrm{mg}$ and $60-\mathrm{mg}$ groups had a $50 \%$ dose reduction, to 15 - and $30-\mathrm{mg}$ edoxaban, respectively. CLCR, creatinine clearance; NA, not available; NSAIDs, non-steroidal anti-inflammatory drugs; SD, standard deviation; SRI, severe renal impairment.

sation or decreased dosing were discontinued from the study (Supplementary File 1).

\section{Dose Selection for SRI Patients}

Based on a pharmacokinetic (PK) study in patients with renal impairment, ${ }^{14}$ the exposure to edoxaban in patients with SRI receiving edoxaban $15 \mathrm{mg}$ is expected to be similar to that of patients with MiRI receiving edoxaban $30 \mathrm{mg}$, or less than that in patients with normal renal function receiving edoxaban $60 \mathrm{mg}$. In addition, population PK analysis with data collected from 15 Phase 1 and 2 studies revealed that the probability of any bleeding event increased with increasing edoxaban exposure. ${ }^{11}$ On the basis of these results, a dose of edoxaban $15 \mathrm{mg}$ once daily was selected for SRI patients in the present study to ensure that the bleeding risk associated with edoxaban was maintained within an acceptable range.

\section{Assessments and Sample Collections}

Investigations, observations, examinations, and the collection of blood and urine samples for hematology, blood biochemistry tests, and urinalysis were performed at screening, at Weeks $2,4,6,8,10$, and 12 (or at discontinuation), and at the 2-week follow-up visit. Adverse events (AEs) and thromboembolic events were recorded from the time of pretreatment assessment up until the end of follow-up.

Blood samples for determination of edoxaban plasma concentrations were collected during Weeks 2 and 8 at pre-dose (trough), $1-3 \mathrm{~h}$ post-dose, $4-8 \mathrm{~h}$ post-dose, and at discontinuation. Edoxaban plasma concentrations were measured at Advion BioServices, Inc (Ithaca, NY, USA), using liquid chromatography-tandem mass spectrometry. The lower limit of quantification for edoxaban was $0.764 \mathrm{ng} / \mathrm{ml}$.

Blood samples for determination of PT, PT-INR, and activated partial thromboplastin time (aPTT) were collected at the following times: (1) pretreatment assessment; (2) during Weeks 2 and 8 at pre-dose, $1-3 \mathrm{~h}$ post-dose, and $4-8 \mathrm{~h}$ post-dose; (3) pre-dose Week 12; (4) at discontinuation; and (5) 2 weeks after discontinuation (follow-up assessment). Blood samples for the measurement of prothrombin fragment $1+2(\mathrm{~F} 1+2)$, thrombin-anti-thrombin III complex (TAT), and D-dimer were collected at the time of pretreatment assessment, pre-dose during Weeks 2, 8, and 12, at discontinuation, and during the follow-up visit 2 weeks after discontinuation. PT and PT-INR were measured and calculated using a Thromborel S kit (Sysmex Corporation, Hyogo, Japan) containing human placental thromboplastin with an international sensitivity index of 0.98 or 0.93 . Determinations of PT-INR during pretreatment assessment and run-in periods for patients previously receiving warfarin were performed in hospital. All remaining biomarker assessments were performed at a central laboratory (SRL Inc, Tokyo, Japan).

\section{Endpoints}

Safety endpoints included the incidence of major or clinically relevant non-major (CRNM) bleeding, any bleeding (composite of major, CRNM, and minor bleeding), major bleeding, CRNM bleeding, AEs, and adverse drug reactions (ADRs). Bleeding endpoints reflected events from the start of study treatment to the day following completion or discontinuation of study treatment. The incidences of $\mathrm{AE}$ and ADRs are 


\begin{tabular}{|c|c|c|c|}
\hline \multirow[b]{2}{*}{ Type of bleeding } & \multirow{2}{*}{$\begin{array}{c}\text { SRI } \\
\qquad \begin{array}{c}\text { Edoxaban } 15 \mathrm{mg} \\
(\mathrm{n}=50)\end{array}\end{array}$} & \multicolumn{2}{|c|}{ Normal/MiR|‡ } \\
\hline & & $\begin{array}{c}\text { Edoxaban } 30 \mathrm{mg} \\
(\mathrm{n}=22)\end{array}$ & $\begin{array}{c}\text { Edoxaban } 60 \mathrm{mg} \\
(\mathrm{n}=21)\end{array}$ \\
\hline \multicolumn{4}{|l|}{ Any bleeding } \\
\hline $\mathrm{n}(\%)$ & $10(20.0)$ & $5(22.7)$ & $5(23.8)$ \\
\hline $95 \% \mathrm{Cl}$ & $11.2,33.0$ & $10.1,43.4$ & $10.6,45.1$ \\
\hline Absolute difference $^{\dagger}(95 \% \mathrm{Cl})$ & - & $2.7(-15.4,25.2)$ & $3.8(-14.7,26.8)$ \\
\hline \multicolumn{4}{|l|}{ Major or CRNM bleeding } \\
\hline $\mathrm{n}(\%)$ & $0(0.0)$ & $0(0.0)$ & $1(4.8)$ \\
\hline $95 \% \mathrm{Cl}$ & $0.0,7.1$ & $0.0,14.9$ & $0.8,22.7$ \\
\hline Absolute difference $^{\dagger}(95 \% \mathrm{Cl})$ & - & $0.0(-7.1,14.9)$ & $4.8(-3.4,22.7)$ \\
\hline \multicolumn{4}{|l|}{ Major bleeding } \\
\hline $\mathrm{n}(\%)$ & $0(0.0)$ & $0(0.0)$ & $0(0.0)$ \\
\hline $95 \% \mathrm{Cl}$ & $0.0,7.1$ & $0.0,14.9$ & $0.0,15.5$ \\
\hline Absolute difference $^{\dagger}(95 \% \mathrm{Cl})$ & - & $0.0(-7.1,14.9)$ & $0.0(-7.1,15.5)$ \\
\hline \multicolumn{4}{|l|}{ CRNM bleeding } \\
\hline $\mathrm{n}(\%)$ & $0(0.0)$ & $0(0.0)$ & $1(4.8)$ \\
\hline $95 \% \mathrm{Cl}$ & $0.0,7.1$ & $0.0,14.9$ & $0.8,22.7$ \\
\hline Absolute difference $^{\dagger}(95 \% \mathrm{Cl})$ & - & $0.0(-7.1,14.9)$ & $4.8(-3.4,22.7)$ \\
\hline \multicolumn{4}{|l|}{ Minor bleeding } \\
\hline $\mathrm{n}(\%)$ & $10(20.0)$ & $5(22.7)$ & $4(19.0)$ \\
\hline $95 \% \mathrm{Cl}$ & $11.2,33.0$ & $10.1,43.4$ & $7.7,40.0$ \\
\hline Absolute difference $^{\dagger}(95 \% \mathrm{Cl})$ & - & $2.7(-15.4,25.2)$ & $-1.0(-18.3,21.8)$ \\
\hline
\end{tabular}

tThe absolute difference was calculated as the difference between the severe renal impairment (SRI) 15-mg edoxaban group and either the normal renal function/mild renal impairment (normal/MiRI) edoxaban 30-mg or 60-mg

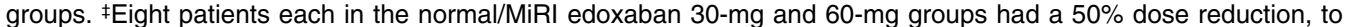
15- and 30-mg edoxaban, respectively. $\mathrm{Cl}$, confidence interval; CRNM, clinically relevant non-major bleeding.

\begin{tabular}{|c|c|c|c|}
\hline \multirow[b]{2}{*}{$\mathrm{AE}$} & \multirow{2}{*}{$\begin{array}{c}\text { SRI } \\
\underset{(n=50)}{\text { Edoxaban } 15 \mathrm{mg}}\end{array}$} & \multicolumn{2}{|c|}{ Normal/MiR ${ }^{\ddagger}$} \\
\hline & & $\begin{array}{l}\text { Edoxaban } 30 \mathrm{mg} \\
(\mathrm{n}=22)\end{array}$ & $\begin{array}{c}\text { Edoxaban } 60 \mathrm{mg} \\
(\mathrm{n}=21)\end{array}$ \\
\hline No. patients with $\geq 1 \mathrm{AE}(\%)$ & $33(66.0)$ & $14(63.6)$ & $10(47.6)$ \\
\hline $95 \% \mathrm{Cl}$ & $52.2,77.6$ & $43.0,80.3$ & $28.3,67.6$ \\
\hline \multicolumn{4}{|l|}{$\begin{array}{l}\text { AEs reported by } \geq 5 \% \text { of patients in any } \\
\text { group }^{\dagger}\end{array}$} \\
\hline Nasopharyngitis & $5(10.0)$ & 4 (18.2) & $5(23.8)$ \\
\hline Pneumonia & $3(6.0)$ & $0(0.0)$ & $0(0.0)$ \\
\hline Epistaxis & $3(6.0)$ & $0(0.0)$ & $0(0.0)$ \\
\hline Gingival bleeding & $1(2.0)$ & $2(9.1)$ & $1(4.8)$ \\
\hline Hemorrhage subcutaneous & $4(8.0)$ & $1(4.5)$ & $0(0.0)$ \\
\hline Hematuria & $3(6.0)$ & $0(0.0)$ & $4(19.0)$ \\
\hline Blood creatinine increased & $4(8.0)$ & $0(0.0)$ & $0(0.0)$ \\
\hline Blood urine present & $2(4.0)$ & $2(9.1)$ & $0(0.0)$ \\
\hline Occult blood & $3(6.0)$ & $0(0.0)$ & $0(0.0)$ \\
\hline Patients with $\geq 1$ ADR & $12(24.0)$ & $4(18.2)$ & $5(23.8)$ \\
\hline $95 \% \mathrm{Cl}$ & $14.3,37.4$ & $7.3,38.5$ & $10.6,45.1$ \\
\hline Patients with $\geq 1$ serious $A E$ & $5(10.0)$ & $0(0.0)$ & $0(0.0)$ \\
\hline $95 \% \mathrm{Cl}$ & $4.3,21.4$ & $0.0,14.9$ & $0.0,15.5$ \\
\hline $\begin{array}{l}\text { Patients with } \geq 1 \mathrm{AE} \text { leading to drug } \\
\text { discontinuation }\end{array}$ & $5(10.0)$ & $0(0.0)$ & $2(9.5)$ \\
\hline $95 \% \mathrm{Cl}$ & $4.3,21.4$ & $0.0,14.9$ & $2.7,28.9$ \\
\hline
\end{tabular}

Unless indicated otherwise, data are presented as $\mathrm{n}(\%)$. ${ }^{\dagger}$ Reported by Medical Dictionary for Regulatory Activities (MedDRA; Version 15.1; http://www.meddra.org/ [accessed October 25, 2011]) preferred terminology. *Eight patients each in the normal renal function or mild renal impairment (normal/MiRl) edoxaban 30-mg and 60-mg groups had a $50 \%$ dose reduction, to $15-$ and $30-\mathrm{mg}$ edoxaban, respectively. $A D R$, adverse drug reaction; $A E$, adverse event. Other abbreviations as in Tables 1,2. 


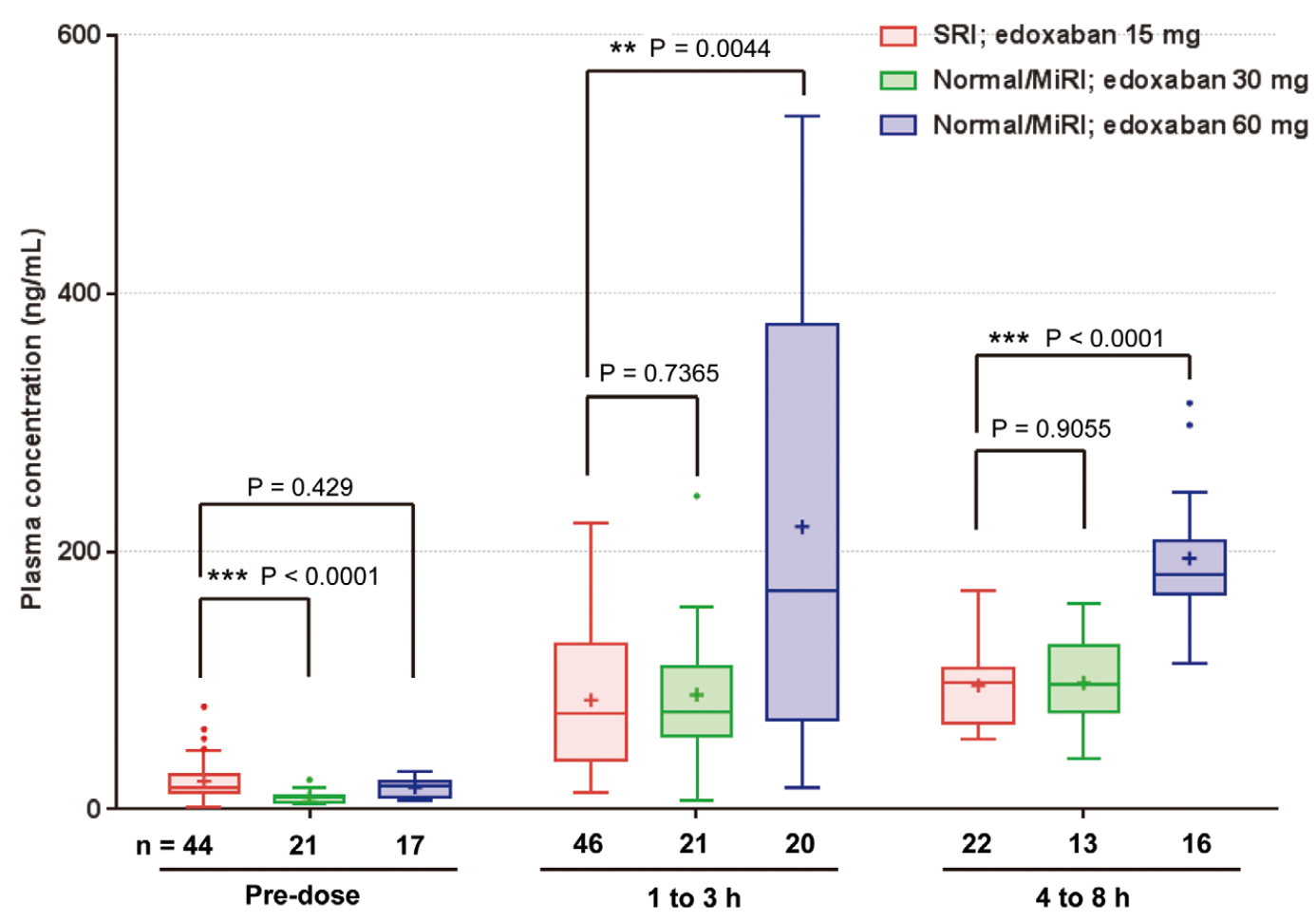

Time points

Figure 2. Plasma edoxaban concentrations in Japanese patients with non-valvular atrial fibrillation (NVAF) and severe renal impairment (SRI; creatinine clearance [CLCR] $\geq 15$ to $<30 \mathrm{ml} / \mathrm{min}$ ) administered edoxaban $15 \mathrm{mg}$ once daily for 12 weeks compared with NVAF patients with normal renal function or mild renal impairment (normal/MiRI; CLCR $\geq 50 \mathrm{ml} / \mathrm{min}$ ) administered edoxaban 30 or $60 \mathrm{mg}$ once daily for 12 weeks. Boxes show lower and upper quartiles, with median values indicated by the horizontal lines. Whiskers represent minimum and maximum values within the 1.5 interquartile range, respectively. Mean values are shown by the "+" sign, whereas outliers are represented by filled circles. Eight patients each in the normal/MiRI edoxaban 30-mg and 60-mg groups had a $50 \%$ dose reduction, to $15 \mathrm{mg}$ and $30 \mathrm{mg}$, respectively. ${ }^{\star \star} \mathrm{P}<0.01,{ }^{\star \star \star} \mathrm{P}<0.001$ compared with the SRI group (Wilcoxon rank sum test).

reported from the start of the run-in period (or at the initiation of treatment if a run-in period was not necessary) to the follow-up visit. Major bleeding was defined on the basis of published guidelines from the International Society on Thrombosis and Haemostasis (ISTH), ${ }^{15}$ with minor modifications for decreased hemoglobin and blood transfusion requirements; CRNM bleeding was defined as clinically overt bleeding that did not meet the criteria of major bleeding but required medical attention. Additional details regarding the definition of major or CRNM bleeding are provided in the Supplementary Material. Minor bleeding was defined as other overt bleeding events that did not meet the criteria for major or CRNM bleeding. All bleeding events were adjudicated by a safety assessments committee blinded to treatment group. The AEs were summarized by system organ class and preferred term according to the Medical Dictionary for Regulatory Activities (Version 15.1; http://www.meddra.org/).

The incidence of thromboembolic events (composite of cerebral infarction and systemic embolism) during the study period (from the start of treatment to the day following completion or discontinuation of study treatment) was assessed as an exploratory analysis.

\section{Statistical Analysis}

All patients enrolled in the study receiving at least 1 dose of study drug, without significant GCP violations, and safety data after the start of study treatment were included in the safety analysis set. Incidences and 95\% confidence intervals (CIs) were calculated by treatment group for major or CRNM bleeding, any bleeding event (major, CRNM, and minor bleeding), and individual types of bleeding events. In addition, absolute differences in the incidence of bleeding events and corresponding 95\% CIs were calculated between the SRI and normal/MiRI groups. Incidences and 95\% CIs of AEs, serious AEs, ADRs, and AEs leading to discontinuation of study drug were also calculated by treatment group.

All patients enrolled in the study receiving $\geq 1$ dose of study drug without significant GCP violations were included in the efficacy analysis set. For the efficacy endpoint (thromboembolic events), incidence and $95 \%$ CIs were calculated by treatment group.

Data from subjects with valid plasma drug concentrations and biomarker data measured at $\geq 1$ time point were included in descriptive statistics and were calculated by treatment group at each time point. For comparison of edoxaban plasma con- 


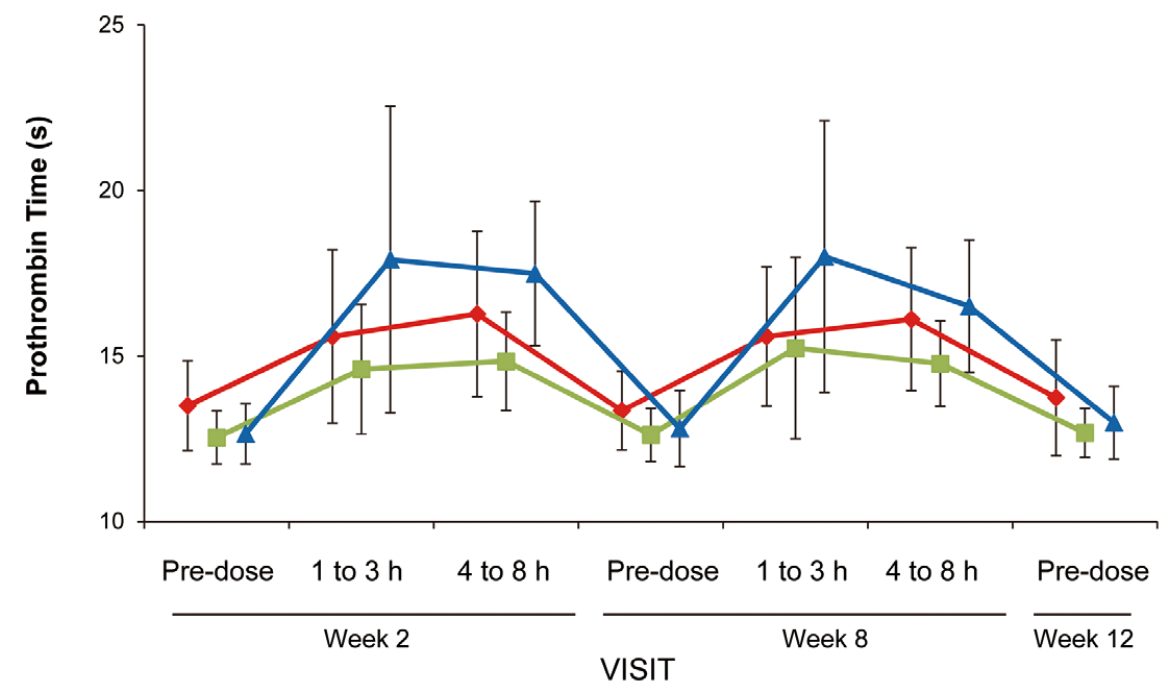

\begin{tabular}{|c|c|c|c|c|c|c|c|}
\hline \multirow{2}{*}{\multicolumn{8}{|c|}{ SRI }} \\
\hline & & & & & & & \\
\hline Edoxaban $15 \mathrm{mg} \bullet$ & 45 & 45 & 21 & 40 & 40 & 18 & 37 \\
\hline \multicolumn{8}{|l|}{ Normal/MiRI } \\
\hline Edoxaban $30 \mathrm{mg}^{*}$ & 21 & 21 & 13 & 21 & 21 & 14 & 21 \\
\hline \multicolumn{8}{|l|}{ Normal/MiRI } \\
\hline Edoxaban $60 \mathrm{mg}^{*}$ & 19 & 20 & 16 & 19 & 19 & 16 & 18 \\
\hline
\end{tabular}

Figure 3. Time course of mean prothrombin time over 12 weeks treatment in Japanese patients with non-valvular atrial fibrillation (NVAF) and severe renal impairment (SRI; creatinine clearance [CLCR] $\geq 15$ to $<30 \mathrm{ml} / \mathrm{min}$ ) administered edoxaban $15 \mathrm{mg}$ once daily compared with NVAF patients with normal renal function or mild renal impairment (normal/MiRl; CLcR $\geq 50 \mathrm{ml} / \mathrm{min}$ ) administered edoxaban 30 or $60 \mathrm{mg}$ once daily. ${ }^{*}$ Eight patients each in the normal/MiRl edoxaban 30-mg and 60-mg groups had a $50 \%$ dose reduction, to $15 \mathrm{mg}$ and $30 \mathrm{mg}$, respectively. Data are the mean $\pm S D$. Values below the graph indicate number of patients per group at each timepoint.

centrations between the SRI and normal/MiRI groups, the Wilcoxon rank sum test was performed. Comparisons between the SRI and normal/MiRi groups for D-dimer, F1+2, and TAT were performed by Student's t-test, whereas comparisons of these measures at different time points within each treatment group were performed by paired t-test. A post hoc multivariate analysis was performed to identify independent predictors for elevation of each biomarker (D-dimer, F1+2) with patient baseline factors (sex, age, body weight, serum creatinine, congestive heart failure, hypertension, PT-INR) as explanatory variables.

All 95\% CIs were calculated using the exact Clopper and Pearson confidence interval method. All statistical analyses were performed using SAS Version 9.2 (SAS Institute, Cary, NC, USA).

In all, 90 patients were planned for enrollment in the study: 50 patients in the SRI group was determined to provide a $95 \%$ probability of detecting major or CRNM bleeding in $\geq 1$ patient, assuming an incidence of major or CRNM bleeding of $6.0 \%$. The number of patients in each of the normal/MiRI groups was set at 20 for adequate assessment of plasma drug concentration data.

\section{Results}

\section{Patients}

A total of 93 patients was enrolled in the study; 50 with SRI and 43 with normal/MiRI (Figure 1). Of the normal/MiRI patients, 22 and 21 patients were randomized to receive edoxaban 30 and $60 \mathrm{mg}$, respectively. Eight patients each in the normal/MiRI edoxaban 30-mg and 60-mg groups received a $50 \%$ dose reduction to 15 and $30 \mathrm{mg}$, respectively.

Patients were mostly male, with a smaller percentage of males in the SRI 15-mg group compared with both normal/ MiRI groups (Table 1). Patients with SRI had a higher mean age and $\mathrm{CHADS}_{2}$ score, and lower mean CLCR and body weight than both normal/MiRI groups. More than $80 \%$ of all patients received warfarin as thromboprophylaxis prior to enrollment.

\section{Safety and Efficacy Analyses}

There were no notable differences in the incidence of any bleeding events between the SRI 15-mg group and both normal/MiRI groups (Table 2), with absolute differences $(95 \%$ CI) between the normal/MiRI 30-mg or 60-mg groups and the SRI 15-mg group of $2.7 \%(-22.1 \%, 27.2 \%)$ or $3.8 \%(-21.7 \%$, $28.8 \%$ ), respectively. No major bleeding events occurred in any treatment group. CRNM bleeding occurred in 1 patient in the normal/MiRI 60-mg group (hematuria). All bleeding events in the SRI 15-mg group were minor.

Of the patients in the normal/MiRI $60-\mathrm{mg}$ group, $62.5 \%$ $(5 / 8)$ who received a dose reduction and $38.5 \%$ (5/13) who received the full $60-\mathrm{mg}$ dose reported $\geq 1 \mathrm{AE}$. At least $1 \mathrm{AE}$ was reported by $50.0 \%$ (4/8) of patients with a dose reduction to $15 \mathrm{mg}$ and by $71.4 \%(10 / 14)$ of patients in the normal/MiRI 30-mg group who received the full dose. The AEs reported by 
Week 2

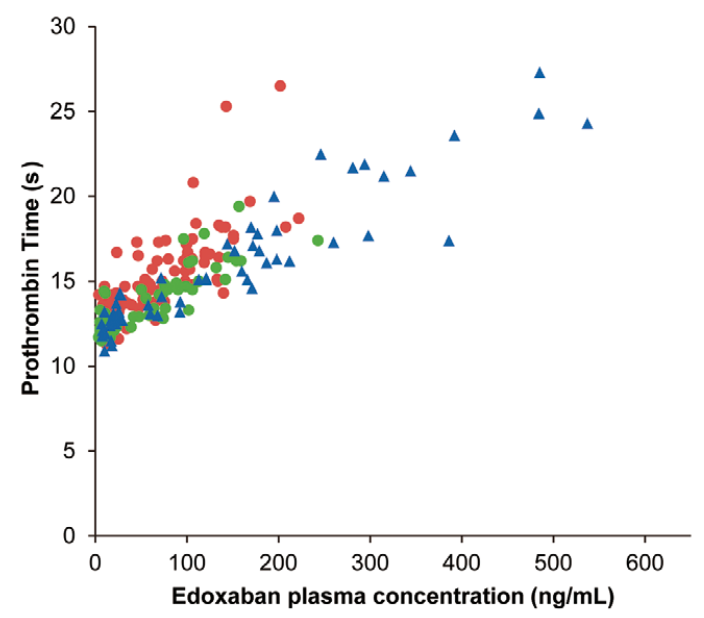

Week 8

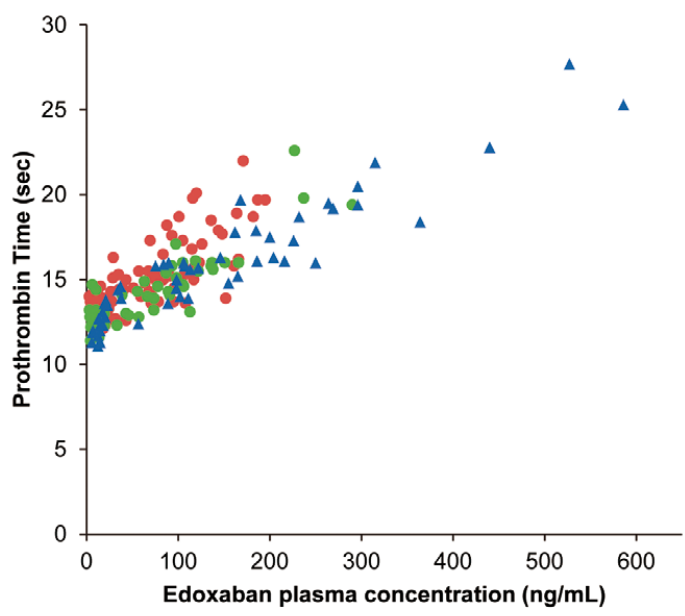

$\Delta$ Normal/MiRl; edoxaban $60 \mathrm{mg}^{*}$

$\Delta \mathrm{Normal} / \mathrm{MR}$; edoxaban $60 \mathrm{mg}$

- SRI; edoxaban $15 \mathrm{mg}$

- Normal/MiRl; edoxaban 30 mg*

Figure 4. Relationship between plasma edoxaban concentrations and prothrombin time at Weeks 2 and 8 in Japanese patients with non-valvular atrial fibrillation (NVAF) and severe renal impairment (SRI; creatinine clearance [CLcR] $\geq 15$ to $<30 \mathrm{ml} / \mathrm{min}$ ) administered edoxaban $15 \mathrm{mg}$ once daily compared with NVAF patients with normal renal function or mild renal impairment (normal/ $\mathrm{MiRI} ; \mathrm{CLCR} \geq 50 \mathrm{ml} / \mathrm{min}$ ) administered edoxaban 30 or $60 \mathrm{mg}$ once daily. ${ }^{*}$ Eight patients each in the normal/MiRI edoxaban $30-\mathrm{mg}$ and $60-\mathrm{mg}$ groups had a $50 \%$ dose reduction, to $15 \mathrm{mg}$ and $30 \mathrm{mg}$, respectively.

$\geq 5 \%$ of patients in any treatment group were mostly related to infection or bleeding (Table 3). The most common ADR was blood in the urine, reported as either "hematuria" or "blood urine present" in $5(10.0 \%), 2(9.1 \%)$, and $4(19.0 \%)$ patients in the SRI 15-mg, normal/MiRI 30-mg, and normal/MiRI 60-mg groups, respectively. No patient experienced increases in alanine aminotransferase or aspartate aminotransferase levels $\geq 3$ times the upper limit of normal (ULN), and 3 patients in the normal/MiRI 30-mg group and 4 patients in the normal/ MiRI 60-mg group had total bilirubin elevation $\geq 1$.5-fold the ULN.

Seven serious AEs were reported in 5 patients in the SRI 15-mg group; none was considered related to the study drug. Pneumonia, exacerbation of existing congestive heart failure, and ventricular tachycardia were reported by a single patient. One patient, with a history of congestive heart failure, reported cardiac failure and pneumonia; another patient reported pleurisy and pneumonia. AEs leading to discontinuation occurred most frequently in the SRI 15-mg group (5 patients): 2 patients had increased blood creatinine, and 1 patient each reported anemia, labile hypertension, and prolonged PT. Two patients in the normal/MiRI 60-mg group discontinued due to an AE: 1 due to erythema and 1 due to hematuria. No patients discontinued due to AEs in the normal/MiRI 30-mg group. No deaths occurred during the study.

There were no reported incidences of thromboembolic events in any of the treatment groups.

\section{Plasma Edoxaban Concentrations}

At Week 2, median (minimum-maximum) predose plasma edoxaban concentration in the SRI 15-mg group (17.4 [2.45$79.8] \mathrm{ng} / \mathrm{ml}$ ) was significantly higher than in the normal/MiRI 30-mg group (9.66 [3.88-23.2] ng/ml; $\mathrm{P}<0.0001)$ and similar to that in the normal/MiRI 60-mg group (18.2 [6.86-29.5] $\mathrm{ng} / \mathrm{ml}$; Figure 2). At $1-3 \mathrm{~h}$ and $4-8 \mathrm{~h}$ post-dose at Week 2 , the median (minimum-maximum) plasma edoxaban concentrations in the SRI $15 \mathrm{mg}$-group (74.4 [13.3-222.0] and 98.3 [54.4-169.0] ng/ml, respectively) were similar to those in the normal/MiRI 30-mg group (75.7 [7.2-243.0] and 96.5 [39.2159] $\mathrm{ng} / \mathrm{ml}$, respectively) and significantly lower than in the normal/MiRI 60-mg group (170 [16.7-537.0] and 182 [113.0$315.0] \mathrm{ng} / \mathrm{ml}$, respectively; $\mathrm{P}=0.0044$ and $\mathrm{P}<0.0001$ respectively; Figure 2). At Week 8, edoxaban plasma concentrations and the relationship between edoxaban plasma concentrations and the treatment groups were generally similar to those at Week 2 for all treatment groups (data not shown).

\section{Biomarkers}

Mean PT values in the SRI 15-mg group were between those in the normal/MiRI 30-mg and 60-mg groups at each time point at Weeks 2, 8, and 12, except for the pre-dose value at each week (Figure 3). The time courses for PT-INR and aPTT in the SRI 15-mg group were also between those in the nor$\mathrm{mal} / \mathrm{MiRI}$ 30-mg and 60-mg edoxaban groups at Weeks 2 and 8 , except for pre-dose data (Figures S1,S2). At Weeks 2 and 8 , PT was prolonged as plasma edoxaban concentration increased. This relationship did not differ between the treatment groups by visual assessment (Figure 4). Similar prolongations with increased edoxaban plasma concentrations were seen for PT-INR and aPTT at Weeks 2 and 8 (data not shown).

From the pretreatment assessment to follow-up, F1+2 and D-dimer levels were significantly higher in the SRI 15-mg group than in the normal/MiRI groups at each time point (F1+2, $\mathrm{P}<0.05$ [Figure S3]; D-dimer, $\mathrm{P}<0.001$ [Figure 5]), 


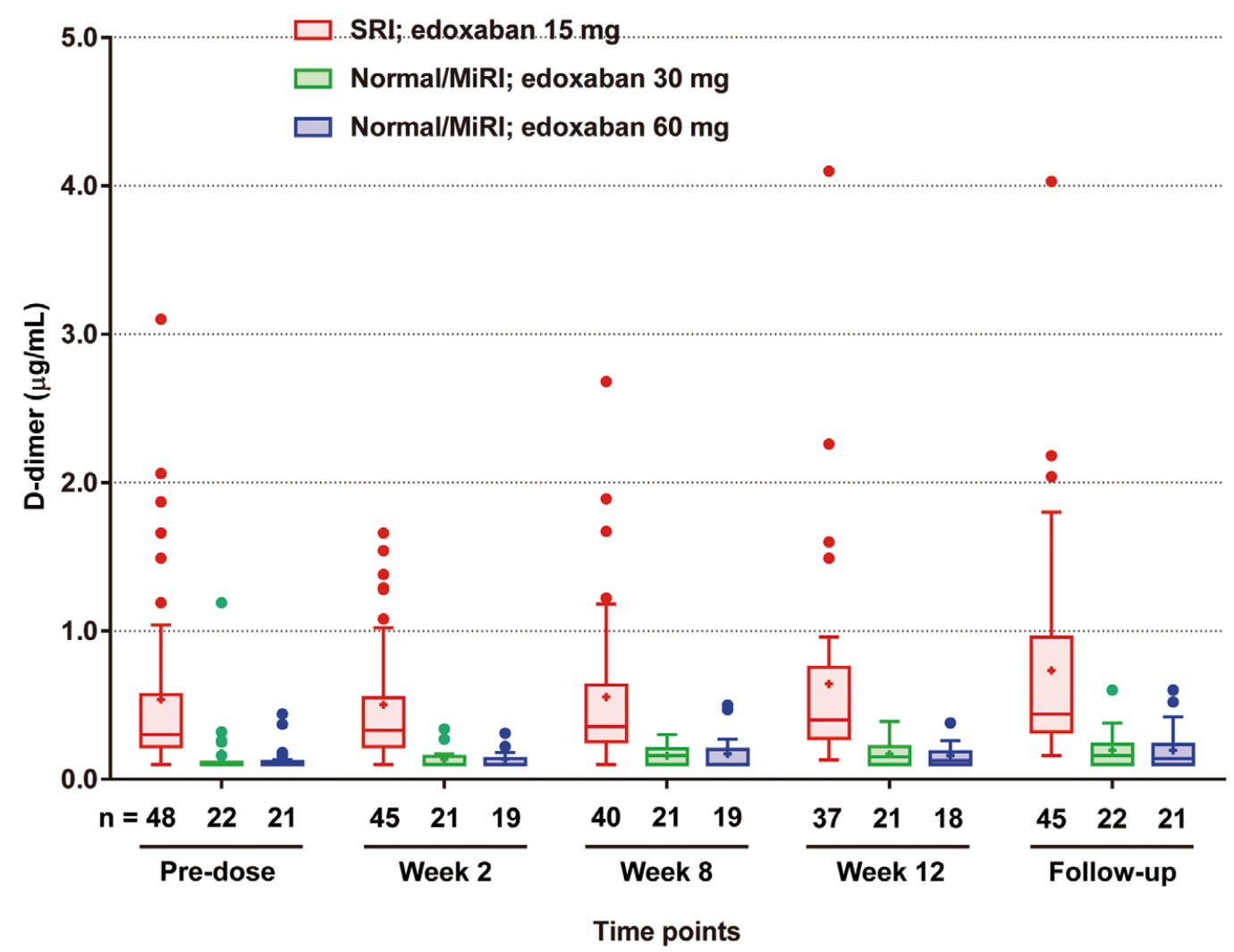

Figure 5. D-Dimer concentrations in Japanese patients with non-valvular atrial fibrillation (NVAF) and severe renal impairment (SRI; creatinine clearance $[\mathrm{CLCR}] \geq 15$ to $<30 \mathrm{ml} / \mathrm{min}$ ) administered edoxaban $15 \mathrm{mg}$ once daily compared with NVAF patients with normal renal function or mild renal impairment (normal/MiRI; CLcR $\geq 50 \mathrm{ml} / \mathrm{min}$ ) administered edoxaban 30 or $60 \mathrm{mg}$ once daily. Boxes show lower and upper quartiles, with median values indicated by the horizontal lines. Whiskers represent minimum and maximum values within the 1.5 interquartile range, respectively. Mean values are shown by the "+" sign, whereas outliers are represented by circles. Eight patients each in the normal/MiRI edoxaban 30-mg and 60-mg groups had a 50\% dose reduction, to $15 \mathrm{mg}$ and $30 \mathrm{mg}$, respectively.

whereas TAT levels were significantly higher only at Week 8 $(\mathrm{P}<0.01$; data not shown). No notable changes in mean D-dimer plasma concentrations were observed in any treatment group during the study period, except for at Week 12 in the normal/ MiRI $60 \mathrm{mg}$ group $(\mathrm{P}<0.05$ at Week 12). Mean $\mathrm{F} 1+2$ in all treatment groups was significantly higher during the predose assessments at Weeks 2, 8, and 12 than at pretreatment assessment $(\mathrm{P}<0.01)$. At follow-up assessment, mean $\mathrm{F} 1+2$ returned to similar levels as those obtained at the pretreatment assessment in all treatment groups (all follow-up time points vs. pretreatment: not significant by paired t-test). No notable changes in mean TAT from pretreatment assessment were found from Week 2 to the follow-up assessment in any treatment group (data not shown; all points vs. pretreatment not significant by paired t-test). At pretreatment, post hoc multivariate analysis revealed a direct significant relationship between pretreatment $\mathrm{D}$-dimer and patient baseline factors of age $(\mathrm{P}=0.0433)$, serum creatinine $(\mathrm{P}=0.0015)$, and $\mathrm{PT}-\mathrm{INR}$ $(\mathrm{P}=0.0253)$. Baseline age $(\mathrm{P}=0.0285)$ and serum creatinine $(\mathrm{P}=0.0219)$ were significantly associated with $\mathrm{D}$-dimer at Week 12. Baseline age $(\mathrm{P}=0.0126)$ and $\mathrm{PT}-\mathrm{INR}(\mathrm{P}<0.0001)$ exhibited a significant direct relationship with $\mathrm{F} 1+2$ at pretreatment. No baseline variables were found to have a signifi- cant relationship with F1+2 at Week 12 .

\section{Discussion}

Data on anticoagulant use for stroke prevention in patients with AF and SRI are limited. The present study is the only study to evaluate the short-term safety and drug plasma concentrations of a NOAC in Japanese patients with NVAF and SRI. Administration of edoxaban $15 \mathrm{mg}$ once daily in patients with SRI did not markedly increase bleeding compared with patients with normal/MiRI who received edoxaban 30 or $60 \mathrm{mg}$ once daily for 12 weeks. This suggests that NVAF patients with SRI receiving edoxaban $15 \mathrm{mg}$ may have similar bleeding risks as NVAF patients with normal/MiRI receiving the conventional edoxaban regimen.

Considerable overlap in edoxaban plasma concentrations was seen in patients with SRI receiving edoxaban $15 \mathrm{mg}$ once daily and patients with normal/MiRI receiving edoxaban 30 or $60 \mathrm{mg}$ once daily, which may explain the similar bleeding rates observed across treatments. Edoxaban plasma concentrations observed in the present study for all treatment groups at predose or 4-8h post-dose are consistent with previously reported steady state trough and maximum plasma con- 
centrations. ${ }^{16}$

The low bleeding rates observed in the present study are similar to or lower than those observed in previous edoxaban studies. The incidence of major or CRNM bleeding in the 30-mg and 60-mg edoxaban treatment groups in Phase 2 studies was $1.5 \%$ and $5.4 \%$, respectively, in Japanese NVAF patients ${ }^{17}$ and $3.0 \%$ and $3.8 \%$, respectively, in Eastern Europe. ${ }^{16}$

The incidence and type of AEs in the SRI group were comparable to those in both normal/MiRI groups. Serious AEs were noted only in the SRI group; however, none was considered related to the study drug. The SRI group experienced a higher incidence of AEs leading to discontinuation of study drug. However, there were only 2 AEs (anemia, increased blood creatinine) that were considered related to the study drug and, because patients with SRI were generally older, at higher risk, and in poorer health than patients with normal/ MiRI, these events did not contradict the known safety profile of edoxaban.

No thromboembolic events occurred in any treatment group over the 12-week course of edoxaban treatment. However, it should be noted that the present study was not designed to assess efficacy. Because the annualized event rate for stroke or SEE in patients receiving an oral anticoagulant is $\leq 2 \%,{ }^{12,18,19}$ the duration and sample size of the present study were not adequate for efficacy assessment, which requires a longer duration and greater patient numbers.

The biomarker profile of edoxaban in patients with SRI was consistent with the known biomarker profile of edoxaban in healthy patients. ${ }^{20}$ In the present study, PT, PT-INR, and aPTT at Week 2 were prolonged as plasma edoxaban concentrations increased. In addition, the relationships between plasma edoxaban concentrations and PT, PT-INR, or aPTT were not affected by the severity of renal impairment in patients with NVAF. Although $96 \%$ of the SRI patients received anticoagulant therapy before pretreatment assessment, D-dimer plasma concentrations were higher in the SRI group than in both normal/ MiRI groups during the study period. No notable changes in D-dimer concentrations were observed during the treatment period in any treatment groups, except at Week 12 in the normal/MiRI 60-mg edoxaban group. Furthermore, higher D-dimer levels observed in the SRI group did not translate to an increased incidence of thromboembolic events. Higher D-dimer levels are significantly associated with decreased renal function in individuals with and without NVAF, ${ }^{3,21}$ thus the observed elevation in D-dimer levels in the SRI group in the present study may be a reflection of renal dysfunction in this group. Similarly, mean F1+2 levels were higher in the SRI group than in both normal/MiRI groups during the study period. The significantly lower levels of $\mathrm{F} 1+2$ in all groups observed at the pretreatment and follow-up assessments compared with the levels during edoxaban treatment were likely due to warfarin treatment.

In post hoc multivariate analysis, age, serum creatinine, and PT-INR were selected as predictors of increases in D-dimer at pretreatment. Age and renal impairment are related to the coagulation and fibrinolytic system, ${ }^{3,21}$ and the results of this analysis were considered appropriate in this context. PT-INR was selected as a predictor of D-dimer elevation at pretreatment due to warfarin treatment and removed as a predictor at Week 12 due to anticoagulant treatment switching from warfarin to edoxaban. The D-dimer concentrations after initiation of edoxaban treatment were similar to pretreatment levels. However, when individual D-dimer values were classified as within the normal range or higher than the normal range based on a $1 \mu \mathrm{g} / \mathrm{ml}$ threshold, the proportion of values higher than the normal range decreased from $9.9 \%$ (9/91 patients) at pretreatment to $5.3 \%$ (4/76) at Week 12 (data not shown), likely due to the dose-dependent effect of edoxaban on D-dimer. ${ }^{22}$

There are limited data regarding the use of other NOACs (dabigatran, rivaroxaban, or apixaban) in patients with NVAF and SRI, because this patient population was generally excluded in Phase 3 trials. Considering the known association between $\mathrm{AF}$ and $\mathrm{CKD}$, and the further increased risk of stroke in patients with $\mathrm{AF}$ and $\mathrm{CKD},{ }^{4,23}$ our results provide muchneeded data regarding the safety of an oral anticoagulant in this patient population.

The objective of the present study was to evaluate the shortterm safety and plasma concentrations of edoxaban in patients with NVAF and SRI; therefore, as noted previously, the study was not adequately powered to statistically determine any differences in the incidence of thromboembolic or bleeding events. In addition, the present study was limited because it was conducted in a small population of Japanese patients over a short study period of 12 weeks. Further studies, of longer duration, are needed in larger populations to fully understand the safety, efficacy, and plasma concentration profiles of edoxaban in patients with NVAF and SRI.

\section{Conclusions}

The results of the present short-term study suggest that edoxaban $15 \mathrm{mg}$ once daily does not increase the risk of bleeding in patients with SRI and NVAF and provides similar safety, plasma concentration, and biomarker profiles as that observed in patients with normal renal function or MiRI who receive either edoxaban 30 or $60 \mathrm{mg}$ once daily.

\section{Acknowledgments}

Daiichi-Sankyo Company, Ltd sponsored this study and was involved in the design of the study and the analysis of the data. Writing and statistical support was provided by Takehiro Hagiwara, Kenichi Sakakura, and Atsushi Takita (Daiichi Sankyo Co Ltd); writing and editorial support was provided by Terri Schochet, PhD, and Meryl Gersh, PhD (AlphaBioCom, King of Prussia, PA, USA), and funded by Daiichi Sankyo, Inc (Parsippany, NJ, USA).

\section{Disclosures}

T.K., M.F., and K.A. are employees of Daiichi Sankyo. Y.K. has received remuneration from Boehringer Ingelheim, Bayer, Bristol-Myers Squibb, Pfizer, and Daiichi Sankyo, and scholarship funds or donations from Boehringer Ingelheim. T.Y. has received remuneration from Boehringer Ingelheim, Daiichi Sankyo, Bayer Healthcare, Pfizer, Bristol-Myers Squibb, Eisai, Tanabe-Mitsubishi, and Ono Pharmaceutical, manuscript fees from Boehringer Ingelheim, and scholarship funds or donations from Boehringer Ingelheim, Daiichi Sankyo, and Tanabe-Mitsubishi. M.Y. has received remuneration from Nippon Boehringer Ingelheim, Bayer Yakuhin, and Bristol-Myers Squibb.

\section{References}

1. Inoue H, Fujiki A, Origasa H, Ogawa S, Okumura K, Kubota I, et al. Prevalence of atrial fibrillation in the general population of Japan: An analysis based on periodic health examination. Int J Cardiol 2009; 137: 102-107.

2. Imai E, Horio M, Watanabe T, Iseki K, Yamagata K, Hara S, et al. Prevalence of chronic kidney disease in the Japanese general population. Clin Exp Nephrol 2009; 13: 621-630.

3. Tanaka H, Sonoda M, Kashima K, Tanaka Y, Nakamura K, Nuruki $\mathrm{N}$, et al. Impact of decreased renal function on coagulation and fibrinolysis in patients with non-valvular atrial fibrillation. Circ J 2009; 73: $846-850$.

4. Go AS, Fang MC, Udaltsova N, Chang Y, Pomernacki NK, Borowsky L, et al. Impact of proteinuria and glomerular filtration rate on risk of thromboembolism in atrial fibrillation: The anticoagulation and risk factors in atrial fibrillation (ATRIA) study. Circulation 2009; 119: $1363-1369$. 
5. JCS Joint Working Group. Guidelines for pharmacotherapy of atrial fibrillation (JCS 2013) (in Japanese). http://www.j-circ.or.jp/ guideline/pdf/JCS2013_inoue_h.pdf (accessed May 8, 2014).

6. Prazaxa capsules (dabigatran etexilate) [package insert]. Tokyo: Boehringer Ingelheim, 2013 (in Japanese).

7. Xarelto tablets (rivaroxaban) [package insert]. Osaka: Bayer, 2012 (in Japanese).

8. Eliquis tablets (apixaban) [package insert]. Tokyo: Pfizer, 2013 (in Japanese).

9. Furugohri T, Isobe K, Honda Y, Kamisato-Matsumoto C, Sugiyama $\mathrm{N}$, Nagahara T, et al. DU-176b, a potent and orally active factor Xa inhibitor: In vitro and in vivo pharmacological profiles. J Thromb Haemost 2008; 6: $1542-1549$.

10. Bathala MS, Masumoto H, Oguma T, He L, Lowrie C, Mendell J. Pharmacokinetics, biotransformation, and mass balance of edoxaban, a selective, direct factor Xa inhibitor, in humans. Drug Metab Dispos 2012; 40: $2250-2255$.

11. Salazar DE, Mendell J, Kastrissios H, Green M, Carrothers TJ, Song $\mathrm{S}$, et al. Modelling and simulation of edoxaban exposure and response relationships in patients with atrial fibrillation. Thromb Haemost 2012; 107: 925-936.

12. Giugliano RP, Ruff CT, Braunwald E, Murphy SA, Wiviott SD, Halperin JL, et al. Edoxaban versus warfarin in patients with atrial fibrillation. N Engl J Med 2013; 369: 2093-2104.

13. Cockcroft DW, Gault MH. Prediction of creatinine clearance from serum creatinine. Nephron 1976; 16: 31-41.

14. Ridout G, de la Motte S, Niemczyk S, Sramek P, Johnson L, Jin J, et al. Effect of renal function on edoxaban pharmacokinetics (PK) and on population PK/PD model. J Clin Pharmacol 2009; 49: 1124 (abstract 1144)

15. Schulman S, Kearon C; Subcommittee on Control of Anticoagulation of the Scientific and Standardization Committee of the International Society on Thrombosis and Haemostasis. Definition of major bleeding in clinical investigations of antihemostatic medicinal products in non-surgical patients. J Thromb Haemost 2005; 3: 692-694

16. Weitz JI, Connolly SJ, Patel I, Salazar D, Rohatagi S, Mendell J, et al. Randomised, parallel-group, multicentre, multinational phase 2 study comparing edoxaban, an oral factor Xa inhibitor, with warfarin for stroke prevention in patients with atrial fibrillation. Thromb Haemost 2010; 104: 633-641.

17. Yamashita T, Koretsune Y, Yasaka M, Inoue H, Kawai Y, Yamaguchi $\mathrm{T}$, et al. Randomized, multicenter, warfarin-controlled phase II study of edoxaban in Japanese patients with non-valvular atrial fibrillation. Circ J 2012; 76: 1840-1847.
18. Hart RG, Pearce LA, Aguilar MI. Meta-analysis: Antithrombotic therapy to prevent stroke in patients who have nonvalvular atrial fibrillation. Ann Intern Med 2007; 146: 857-867.

19. Lip GY, Frison L, Grind M; SPORTIF Investigators. Stroke event rates in anticoagulated patients with paroxysmal atrial fibrillation. $J$ Intern Med 2008; 264: 50-61.

20. Ogata K, Mendell-Harary J, Tachibana M, Masumoto H, Oguma T, Kojima M, et al. Clinical safety, tolerability, pharmacokinetics, and pharmacodynamics of the novel factor Xa inhibitor edoxaban in healthy volunteers. J Clin Pharmacol 2010; 50: 743-753.

21. Shlipak MG, Fried LF, Crump C, Bleyer AJ, Manolio TA, Tracy RP, et al. Elevations of inflammatory and procoagulant biomarkers in elderly persons with renal insufficiency. Circulation 2003; 107: 87-92.

22. Fuji T, Fujita S, Tachibana S, Kawai Y. A dose-ranging study evaluating the oral factor Xa inhibitor edoxaban for the prevention of venous thromboembolism in patients undergoing total knee arthroplasty. J Thromb Haemost 2010; 8: 2458-2468.

23. Watanabe H, Watanabe T, Sasaki S, Nagai K, Roden DM, Aizawa Y. Close bidirectional relationship between chronic kidney disease and atrial fibrillation: The Niigata preventive medicine study. Am Heart J 2009; 158: 629-636.

\section{Supplementary Files}

Supplementary File 1

\section{Methods}

Figure S1. Time course of mean prothrombin time expressed as the international normalized ratio (PT/INR) after edoxaban treatment in patients with severe renal impairment (SRI) or normal renal function or mild renal impairment (normal/MiRI).

Figure S2. Time course of mean activated partial thromboplastin time (aPTT) after edoxaban treatment in patients with severe renal impairment (SRI) or normal renal function or mild renal impairment (normal/MiRI).

Figure S3. Time course of mean prothrombin fragment $1+2(\mathrm{~F} 1+2)$ after edoxaban treatment in patients with severe renal impairment (SRI) or normal renal function or mild renal impairment (normal/ MiRI).

Please find supplementary file(s);

http://dx.doi.org/10.1253/circj.CJ-14-0942 